\title{
LA PERCEPCIÓN SOBRE LA RESPONSABILIDAD SOCIAL EN LAS SOCIEDADES COOPERATIVAS DE TRABAJO ASOCIADO Y LAS SOCIEDADES LABORALES: UN ANÁLISIS EN EL ÁMBITO DE LA CIUDAD DE MADRID
}

\author{
POR \\ Juan Carlos GARCÍA VILLALOBOS' \\ Javier ITURRIOZ DEL CAMPO, \\ José Luis MATEU GORDON, y \\ Ricardo PALOMO ZURDO*
}

\section{RESUMEN}

Esta investigación analiza la percepción de las empresas de participación o de economía social de la ciudad de Madrid, en concreto de las sociedades cooperativas de trabajo asociado y de sociedades laborales, sean anónimas o limitadas, sobre diferentes aspectos relativos a la denominada Responsabilidad Social Corporativa. El trabajo realizado se basa en la obtención de las valoraciones de los responsables de las sociedades objeto de estudio, a través de un cuestionario dirigido a una muestra de estas empresas, el cual ha sido complementado con reuniones de trabajo y entrevistas personales. En el mismo se ha podido constatar que existe cierta preocupación y concienciación sobre la responsabilidad de las empresas con la sociedad y su entorno, sobre todo por parte de los socios trabajadores de estas empresas. Por otro lado, también se ha detectado que es necesario fomentar la asunción de los criterios socialmente responsables por parte de las empresas, potenciar el desarrollo de memorias de sostenibilidad y una mayor implicación de todos los colectivos vinculados con las empresas no sólo los socios trabajadores sino también los socios que sólo aportan capital,

\footnotetext{
* Profesores de la Universidad San Pablo CEU. Dirección de correo electrónico: garvil@ceu.es; itucam@ceu.es; margor@ceu.es; palzur@ceu.es
}

REVESCO N 104 - Primer Cuatrimestre 2011 - ISSN: 1885-8031 - www.ucm.es/info/revesco

DOI: 10.5209/rev_REVE.2011.v104.4

Fecha de recepción: 18/10/2010

Fecha de aceptación: 14/12/2010 
los trabajadores no socios, las administraciones y los proveedores, entre otros; puesto que aún existe cierta distancia en comparación con las actuaciones que llevan a cabo empresas de mayor dimensión.

Palabras clave: Responsabilidad Social Corporativa, empresa de participación, Sostenibilidad, Economía social.

Claves ECONLIT: L300, L260; P130

\title{
THE PERCEPTION OF SOCIAL RESPONSABILITY IN WORKERS COOPERATIVES AND LABOUR MANAGED FIRMS IN THE CITY OF MADRID.
}

\begin{abstract}
This research analyzes the perception of social economic firms - specifically workers cooperatives and labour managed firms located in Madrid - regarding their action in activities of social responsibility. The main information used for this article has been obtained from managerial appraisals by evaluating questionnaires sent to a select number of managers of these companies. At the same time, work meetings and personal interviews were held. The research has concluded a rising concern about society and the environment. Furthermore, the survey indicates the necessity of applying socially responsible criteria and the further use of sustainability reports. These criteria should be implemented by all the groups that are in touch with these companies (such as workers, capital suppliers and government amongst others). However, there is still an important difference if we compare the actions undertaken in this field by larger companies.
\end{abstract}

Keywords: Cooperative social responsibility, Sustainability, Social Economy. 


\section{LA RESPONSABILIDAD SOCIAL CORPORATIVA: MARCO DE REFERENCIA.}

Aunque existen múltiples definiciones, la Responsabilidad Social Corporativa (RSC) puede entenderse como una obligación ética o moral, voluntariamente asumida por las empresas, en reconocimiento de los daños que puedan haberle sido causados a la sociedad por la actividad empresarial (Castillo, 1985). Así, la RSC valora la capacidad de la empresa para desarrollar relaciones con el conjunto de las partes vinculadas a la misma ${ }^{1}$, propietarios, empleados, sindicatos, clientes, proveedores, subcontratistas, asociaciones y entes territoriales relacionados con los aspectos sociales, financieros y medioambientales. Teniendo en cuenta la anterior definición pueden destacarse los siguientes aspectos:

- La voluntariedad por parte de la empresa para la realización de las diferentes acciones. Sin embargo, es habitual solicitar una mayor regulación por parte de la Administración de cara a asegurar unos mínimos.

- Las acciones de RSC se centran en tres aspectos: financieros, sociales y medio ambientales.

- Dentro de los colectivos implicados en lo que se denomina "sociedad" pueden diferenciarse los siguientes grupos de interés ${ }^{2}$ :

- Los interlocutores directos de la empresa. Se trata de los clientes, los proveedores, los empleados y los socios, de manera que, además de establecer con ellos las relaciones básicas contractuales y jurídicas, se deben desarrollar relaciones voluntarias que pongan de manifiesto un comportamiento socialmente responsable.

- Los interlocutores indirectos o entorno. Afecta tanto a la comunidad local donde opera la empresa, como a la sociedad en su conjunto. La sostenibilidad es la cuestión principal, de manera que debe lograrse un equilibrio entre la capacidad de la empresa para mantenerse en el mercado y el desarrollo sostenible económico, social, y medioambiental.

Para ofrecer una garantía de la responsabilidad social de la empresa, existen diferentes sistemas que buscan traducir los principios de responsabilidad empresarial en variables

\footnotetext{
${ }^{1}$ El término de "Partes Interesadas" (Stakeholders) incluye a la persona, comunidad u organización afectada por las operaciones de una entidad o que influye en dichas operaciones. Las partes interesadas pueden ser: internas (empleados) o externas (consumidores, proveedores, socios, comunidad local, et), así como los grupos de interés ausentes (generaciones futuras) a los que la actividad presente de la empresa pueda suponer alguna clase de carga o impacto.

${ }^{2}$ COMUNIDADES EUROPEAS. Dictamen del Comité Económico y Social sobre el Libro Verde - Fomentar un marco europeo para la responsabilidad social de las empresas D.O.C.E. C de 27 de mayo de 2002.
} 
cuantificables, con el fin de determinar si la empresa es o no socialmente responsable. Con este objetivo, se parte del análisis de los instrumentos utilizados en la cuantificación, para posteriormente establecer los principales elementos que se recogen en ellos.

Entre los diferentes instrumentos que se pueden emplear para medir la RSC, hay que destacar los siguientes:

a) Los índices ético-sociales: Los índices ético-sociales buscan recoger a las empresas con mejor comportamiento social y medioambiental dentro de su sector, mediante la cuantificación y ponderación de las distintas dimensiones de responsabilidad de la empresa. Para ello analizan las empresas que cumplen los requisitos establecidos en cada uno de ellos.

b) Las normas (códigos y estándares) de responsabilidad social: Se han creado una serie de normas que recogen las condiciones o valores que una empresa debe cumplir para ser considerada como socialmente responsable. Dentro de estas normas se puede diferenciar:

- Los códigos se refieren a una sola empresa, son establecidos por la propia empresa y no existe una auditoría externa.

- Los estándares se aplican a uno o más sectores, son establecidos por un tercero y llevan implícita auditoría externa.

La información sobre el cumplimiento de las diferentes normas de responsabilidad social es recogida por las empresas en las denominadas "memorias de sostenibilidad". Se trata de documentos que tienen como objetivo informar del comportamiento de una empresa en aspectos vinculados con la responsabilidad social. En el ámbito de las sociedades cooperativas a estos documentos se les ha denominado "balance social".

La medición de la RSC implica una serie de problemas derivados de; la comparabilidad, y la necesidad de auditoria:

- Los problemas de comparabilidad se producen por la heterogeneidad entre los aspectos analizados y la forma de medirlos. Esta circunstancia hace que se produzcan dificultades a la hora de poder comparar el comportamiento empresarial de dos o más empresas con respecto a la RSC. Para solucionar esta cuestión han surgido multitud de 
iniciativas que buscan establecer un marco que permita homogeneizar la información. Dentro de estas iniciativas destaca la Global Reporting Initiative (GRI) ${ }^{3}$, a la que se ha hecho referencia anteriormente.

- La existencia o no de una auditoria es otro de los aspectos a tener en cuenta a la hora de analizar la RSC. La existencia de un organismo externo que valore la información y garantice su credibilidad es un aspecto a tener en cuenta en la RSC (Ruiz “et al”, 289). Entre otras iniciativas puede citarse la norma AA1000 creada como guía para los auditores de los informes de RSC (Belhouari “et all”, 198).

Según el GRI estas memorias se basan en los siguientes contenidos básicos:

- El perfil en el que se define el contexto general en el que se encuentra la empresa.

- Enfoque de la dirección que incluye información sobre el estilo de gestión de la empresa.

- Los indicadores de desempeño, que son una serie de herramientas orientadas a obtener información comparable con respecto a la actuación en materia de responsabilidad social.

A partir del análisis de las principales normas existentes para determinar la RSC se han determinado una serie de principios éticos que son recogidos de forma coincidente en la mayoría ellas. Con el fin de homogeneizar los requisitos exigidos, se han agrupado dentro de dos bloques fundamentales: los interlocutores y el entorno (Brown, Dacin,. 1997)

\begin{tabular}{|l|ll|}
\hline \multicolumn{2}{|c|}{ Cuadro 1: Interlocutores Directos } \\
\hline Propietarios & $\checkmark$ & Eficacia y eficiencia en la gestión. \\
& $\checkmark$ & Reparto del beneficio justo. \\
& $\checkmark$ & Representación y gobierno. \\
& $\checkmark$ & Información sobre la empresa. \\
& $\checkmark$ & Información sobre el sistema de gestión ética. \\
\hline Trabajadores & $\checkmark$ & No discriminación. \\
& $\checkmark$ & Derecho a la privacidad y libertad de opinión. \\
& $\checkmark$ & Derechos religiosos y cívicos. \\
& $\checkmark$ & No utilización del trabajo infantil y el forzoso. \\
& $\checkmark$ & Condiciones de trabajo, salud y seguridad. \\
& $\checkmark$ & Asociación, negociación y gestión participativa. \\
& $\checkmark$ & Salario justo y trato correcto. \\
\hline
\end{tabular}

\footnotetext{
${ }^{3}$ GLOBAL REPORTING INITIATIVE. Guía para la elaboración de Memorias de Sostenibilidad. Holanda:
} Global Reporting Initiative, 2006. Disponible en Internet: http://www.globalreporting.org/ 


\begin{tabular}{|c|ll|}
\hline & $\checkmark$ & Horario de trabajo. \\
& $\checkmark$ & Contrato de trabajo. \\
& $\checkmark$ & Procedimiento, formación e información. \\
& $\checkmark$ & Preparación para la jubilación \\
\hline Clientes & $\checkmark$ & Política de marketing y comunicación. \\
& $\checkmark$ & Excelencia de la atención. \\
& $\checkmark$ & Conocimiento de los daños potenciales de los productos o servicios. \\
& $\checkmark$ & Confidencialidad y honestidad. \\
\hline Proveedores & $\checkmark$ & Criterios de selección de los proveedores. \\
& $\checkmark$ & Apoyo al desarrollo de los proveedores. \\
& $\checkmark$ & Cumplimiento del contrato de manera responsable. \\
& $\checkmark$ & Confidencialidad y honestidad. \\
\hline & \multicolumn{2}{|c|}{ ENTORNO } \\
\hline Competencia & $\checkmark$ & Respeto y veracidad. \\
& $\checkmark$ & Relaciones con la competencia. \\
\hline Estado & $\checkmark$ & Colaboración y transparencia. \\
& $\checkmark$ & Obligaciones fiscales. \\
& $\checkmark$ & No injerencia. \\
& $\checkmark$ & Rechazo de los beneficios ilícitos. \\
& $\checkmark$ & Honestidad y lucha contra la corrupción. \\
\hline Medio & $\checkmark$ & Compromiso de la empresa con la causa ambiental. \\
\hline Ambiente & $\checkmark$ & Educación ambiental. \\
\hline Comunidad & $\checkmark$ & Administración del impacto de la empresa en la Comunidad. \\
& $\checkmark$ & Relaciones con Organizaciones actuantes en la Comunidad. \\
& $\checkmark$ & Desarrollo de mecanismos de apoyo a proyectos sociales. \\
& $\checkmark$ & Respeto a la sociedad y a las comunidades locales. Favoreciendo el \\
& & diálogo. \\
& $\checkmark$ & Igualdad entre nacionales y extranjeros. \\
& $\checkmark$ & Política de operaciones empresariales en zonas de conflicto basadas en la \\
& & seguridad de sus empleados y en el respeto de los derechos humanos \\
\hline &
\end{tabular}

Fuente: Elaboración propia.

\section{OBJETIVO Y METODOLOGÍA DEL TRABAJO PARA LA VALORACIÓN DE LA RESPONSABILIDAD SOCIAL CORPORATIVA EN LAS EMPRESAS DE PARTICIPACIÓN EN LA CIUDAD DE MADRID}

El objetivo de este trabajo, que forma parte de un estudio de mayor envergadura sobre las Empresas de participación y la Responsabilidad Social Corporativa y que queda plasmado en el Libro Blanco de las empresas de participación de trabajo de la ciudad de Madrid, consiste en valorar la situación de las empresas de participación madrileñas ante la denominada Responsabilidad Social Corporativa. 
La investigación se apoya metodológicamente en un cuestionario a las sociedades laborales y sociedades cooperativas de trabajo asociado madrileñas (integradas en sus organizaciones representativas) en el que se sigue la estructura de la Global Reporting Initiative por la cual se establecen los siguientes apartados relacionados con la RSC: Aspectos generales; Dimensión económica; Dimensión ambiental y Dimensión social.

Este cuestionario se complementa con una mesa de trabajo en la que participaron algunas empresas consideradas de referencia por las organizaciones representativas que participan en este trabajo y con entrevistas personales a una muestra seleccionada de empresas. El objetivo fundamental es contrastar los resultados obtenidos de la explotación de los cuestionarios para asentar así las conclusiones que derivan de los mismos y que son la base de las propuestas de actuación que se sugerirán.

El número de sociedades cooperativas de trabajo asociado en la Comunidad Autónoma de Madrid a fecha 31 de diciembre de 2007, excluyendo autónomos (solo se incluyen las sociedades cooperativas con socios en régimen de autónomos que tienen al menos un contratado, es de $473^{4}$ y el número de sociedades laborales es de 2.147, de las cuales 303 son sociedades anónimas y 1.844 son sociedades de responsabilidad limitada 5 .

En estudios precedentes ${ }^{6}$ se concluyó que la fuente referida hacía aparecer una cifra inferior a la de sociedades cooperativas vivas en torno a un $36 \%$ (como consecuencia de la ausencia de entidades cuyos socios cotizaban en el régimen de autónomos y por la ausencia de algunas entidades vivas en los ficheros de cotización) y en el caso de las sociedades laborales en torno a un $17 \%$ (por la ausencia de algunas entidades vivas en los ficheros de cotización).

Así, la cifra estimada de sociedades cooperativas de trabajo asociado con actividad en la Comunidad Autónoma de Madrid es de 643 empresas y de sociedades laborales es de 2.512 empresas.

Según la Base de Datos Sistema de Análisis de Balances Ibéricos (SABI) ${ }^{7}$, del total de Sociedades Cooperativas contenidas en la Comunidad Autónoma de Madrid, las localizadas

\footnotetext{
${ }^{4}$ Extraído de http://www.mtin.es/es/empleo/economiasoc/EconomiaSocial/estadisticas/CooperativasAltaSSxClase/2007/C_1.pdf. Fecha de consulta: 18 de noviembre de 2008.

${ }^{5}$ Extraído de: http://www.mtin.es/es/empleo/economiasoc/EconomiaSocial/estadisticas/SociedadesAltaSSocial/2007/4Trim/B_1.pdf. Fecha de consulta: 18 de noviembre de 2008.

${ }^{6}$ Por ejemplo véase C. GARCÍA-GUTIÉRREZ FERNÁNDEZ, G. LEJARRIAGA PÉREZ DE LAS VACAS, et al. Sociedades Cooperativas de Trabajo Asociado. Análisis societario-laboral y económico-financiero. Madrid: Ministerio de Trabajo y Asuntos Sociales, Subdirección General de Publicaciones, 1997.

${ }^{7}$ Véase http://alfama.sim.ucm.es/bd/sabi.htm. Fecha de consulta: 10 de enero de 2008.
} 
en la ciudad de Madrid representan el 62,06\%. De este modo, la cifra inicialmente estimada de sociedades cooperativas de trabajo asociado con actividad en la ciudad de Madrid se sitúa en 399 empresas. Con respecto a las sociedades laborales las localizadas en la ciudad de Madrid representan el 63,05\%. De este modo, la cifra inicialmente estimada de sociedades laborales con actividad en la ciudad de Madrid se sitúa en 1.584 empresas.

Pero esta cifra ha de ser nuevamente corregida con un coeficiente corrector que se estimó en el primer estudio a partir del fichero facilitado por la Subdirección General de Inscripción, Afiliación y Recaudación en Periodo Voluntario (Área de Inscripción y Afiliación) de la Tesorería General de la Seguridad Social del Ministerio de Trabajo y Asuntos Sociales y con el contraste posterior con las bases de datos registrales y de las organizaciones representativas. Así se obtiene la cifra más aproximada a la realidad de empresas con actividad, que es la base para ofrecer determinados datos cuantitativos en los informes correspondientes.

Siendo el coeficiente corrector aplicable a las sociedades cooperativas de trabajo asociado del 2,67\%, el número de sociedades cooperativas de trabajo asociado activas en la ciudad de Madrid se sitúa en 410 empresas. El coeficiente corrector aplicable a las sociedades laborales es del $20,52 \%$, de modo que a partir del mismo se concluye que el número de sociedades laborales activas en la ciudad de Madrid se sitúa en 1.909 empresas.

\begin{tabular}{|c|c|c|c|}
\hline \multicolumn{4}{|c|}{$\begin{array}{l}\text { Cuadro 2: Total de empresas de participación societarias (S. C. T. A. Y S. L.) con } \\
\text { actividad a } 31.12 .07\end{array}$} \\
\hline NÚMERO DE EMPRESAS & S.C.T.A. & S.L. & TOTAL \\
\hline $\begin{array}{l}\text { Seguridad Social a } 31.12 .07 \\
\text { Comunidad Autónoma de Madrid } \\
(*)\end{array}$ & 473 & 2.147 & 2.620 \\
\hline $\begin{array}{l}\text { Seguridad Social a } 31.12 .07 \\
\text { ajustada Comunidad Autónoma de } \\
\text { Madrid }\end{array}$ & 643 & 2.512 & 3.155 \\
\hline $\begin{array}{lccr}\begin{array}{l}\text { Seguridad } \\
\text { ajustada }\end{array} & \begin{array}{c}\text { Social } \\
\text { ciudad }\end{array} & \text { a } & 31.12 .07 \\
\text { (universo estimado) } & & \text { Madrid } \\
\end{array}$ & 399 & 1.584 & 1.983 \\
\hline Coeficiente corrector & 2,67 & 20,52 & \\
\hline $\begin{array}{l}\text { Sociedades Laborales con } \\
\text { actividad } \\
\text { en la ciudad de } \text { Madrid a } 31.12 .07\end{array}$ & 410 & 1.909 & 2.319 \\
\hline
\end{tabular}

(*) Excluidas empresas con socios en régimen de autónomos. 
Con relación a la muestra seleccionada para la cumplimentación del cuestionario en red se ha seguido un muestreo subjetivo por decisión razonada, identificando un conjunto de empresas de las incluidas en la muestra de referencia considerada representativa por mantenerse la distribución porcentual con relación a variables no cuantitativas y para el que los valores medios de las principales variables cuantitativas consideradas en el análisis no suponía una variación superior al $0,2 \%$.

Las variables que se han tenido en cuenta al efecto han sido: tipo de sociedad; localización; antigüedad; sector de actividad; asociacionismo; número de socios trabajadores y número de trabajadores no socios.

Las muestras seleccionadas han sido de un tamaño de 26 empresas para el caso de las sociedades cooperativas de trabajo asociado y 115 para las sociedades laborales, lo que representa, con relación al conjunto de empresas con actividad, un 6,34\% y un 6,02\%, respectivamente, del total.

\section{LOS RESULTADOS SOBRE LA VALORACIÓN DE LA RESPONSABILIDAD SOCIAL CORPORATIVA EN LAS EMPRESAS DE PARTICIPACIÓN EN LA CIUDAD DE MADRID.}

Para tener una referencia sobre el proceso de asimilación de la RSC por parte de las empresas de participación de trabajo de la Ciudad de Madrid se solicitó, a las sociedades consultadas, una valoración sobre el grado de importancia que tiene la Responsabilidad Social Corporativa, estableciendo una escala de 1 a 5, de menor a mayor importancia. El 94,5 por ciento de las entidades encuestadas asignan algún grado de importancia a la RSC, lo que indica una considerable concienciación en este ámbito. Sin embargo, si se tiene en cuenta el grado de importancia que le otorgan, se observa que más del 64 por ciento de estas entidades le dan un valor entre 1 y 2 sobre 5 . En concreto, de este 64 por ciento, sólo un 28,7 por ciento le otorgan el mayor nivel de importancia. El 36 por ciento le asigna una pequeña importancia (valoración de 3 a 5). Esta circunstancia permite establecer que el proceso de asimilación de la RSC es lento, aunque en los últimos años ha aumentado la importancia que se le da a estos aspectos en los diferentes tipos de entidades estudiadas. 
Analizando únicamente a las entidades que le otorgan algún valor a la RSC se observa que entre las distintas sociedades, tanto en las SALs como CTAs sólo hay, algo más de un 20 por ciento de las entidades que asignan una gran importancia a la RSC (entre los grados $4 \mathrm{y}$ 5). Concretamente se trata del 30,77 por ciento de las CTAs y del 23,69 por ciento de las SLLs. Estos datos indican que sigue predominando una reducida valoración de la RSC, aunque se aprecia como un número considerable de entidades empiezan a concebirla como un elemento a tener en cuenta. La citada situación contrasta con el caso de las SALs en las que sólo un 2,78 por ciento de las entidades que valoran a la RSC lo hacen con un grado de importancia elevado.

Gráfico 1: Valoración por tipos de sociedades de la responsabilidad social corporativa

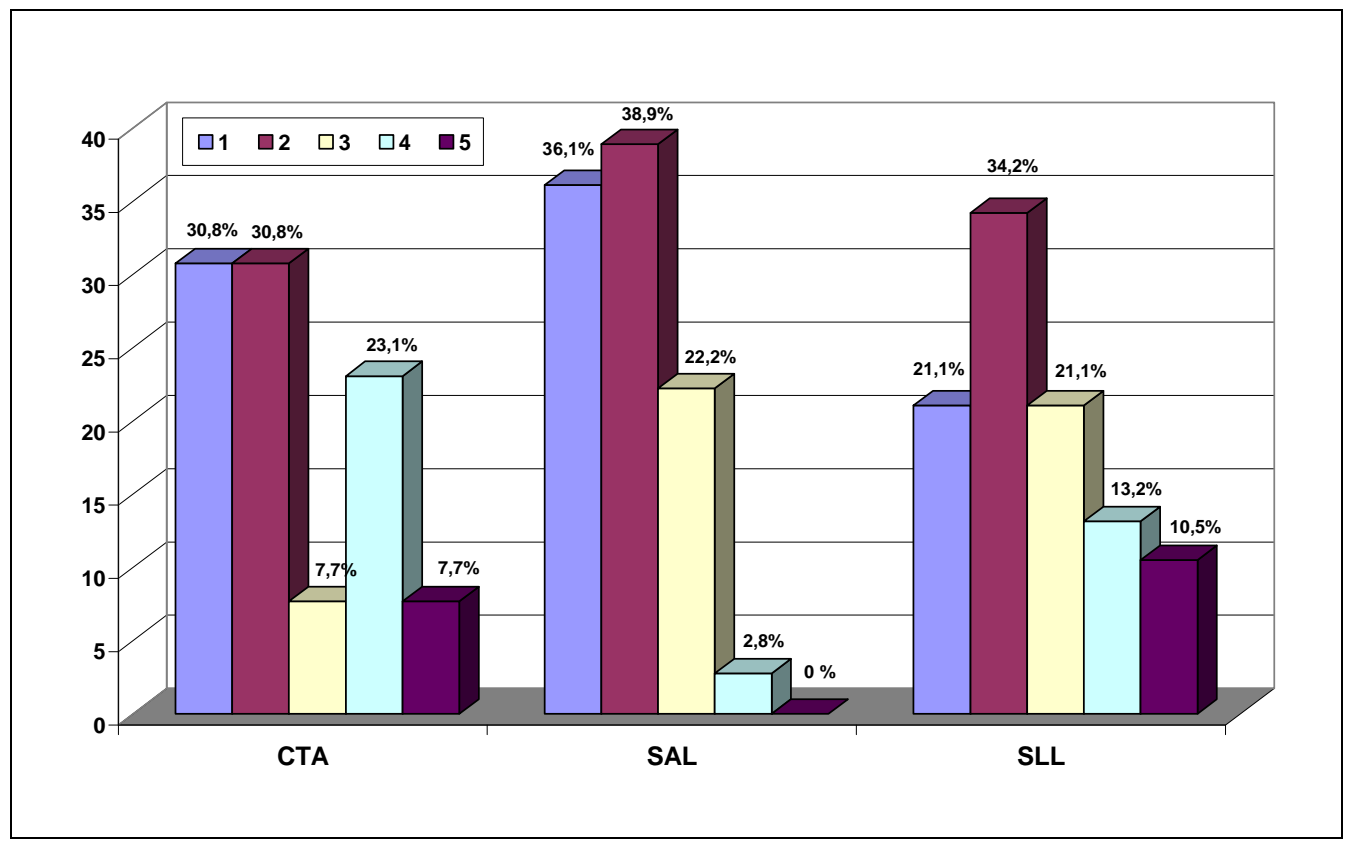

Es importante aumentar la conciencia de que la falta de comportamientos responsables de las empresas entraña considerables riesgos, vinculados con la explotación del medio ambiente y de las materias primas, la intervención de las empresas en la política, o la falta de respeto hacia las condiciones laborales. Por su parte un comportamiento socialmente responsable favorece los intereses de las empresas que desean materializar sus objetivos a largo plazo. Con ello una empresa que invierte requiere unas condiciones generales favorables y estables: seguridad jurídica y paz, una cooperación justa en el seno de la empresa, y un clima social favorable a las inversiones. Todas las empresas deben considerar el entorno social a la hora de tomar sus decisiones. 
A pesar de la creciente mentalización por la RSC, el número de entidades que han publicado memorias de sostenibilidad es muy reducido. Este aspecto debe ser fomentado. En esta línea, aunque la RSC está establecida sobre una base de voluntariedad, diferentes colectivos abogan por una mayor regulación por parte de la Administración Pública. Para ello se han establecido acciones que buscan que las empresas con una mayor dimensión y las que coticen en mercados organizados tengan que publicar informes sobre RSC, pero no se han planteado para empresas de pequeña dimensión ni para autónomos.

Por lo que respecta a la fecha de publicación de estas memorias es bastante reciente, lo que pone de manifiesto que la preocupación por este tipo de problemas está aumentando en los últimos años. En cuanto al formato de publicación de estas memorias destaca el formato impreso, aunque cada vez está ganado más peso la utilización de un formato electrónico o la publicación simultánea en ambos formatos.

En cuanto a la participación de los diferentes colectivos en las acciones vinculadas con la responsabilidad social, se solicitaba indicar de 1 a 5 (5 es la mayor) el nivel de la misma para trabajadores socios, trabajadores no socios, socios no trabajadores, clientes proveedores y administración pública. De los resultados se desprende que son los socios, especialmente los trabajadores (para el 77,3 por ciento de las entidades encuestadas), los mayores partícipes de este tipo de acciones. A continuación destaca la participación de los trabajadores no socios, en el 52,6, lo que está en concordancia con el objetivo general de las empresas de trabajo en las que los aspectos laborales tienen una gran importancia. Los grados de participación descienden considerablemente en los restantes colectivos, siendo el más elevado el de los clientes, con un 35,1 por ciento.

Al diferenciar entre los diferentes tipos societarios se aprecia que la participación por parte de los distintos colectivos mantiene una distribución similar aunque hay que mencionar la escasa participación de los socios no trabajadores en las SCTs con respecto a las sociedades laborales. Esta circunstancia (recogida solamente en un 7,1 por ciento de las SCTs), viene motivada por la prácticamente nula existencia de esta figura. La mayor participación de los socios propietarios de acciones o participaciones no laborales (hasta un 27 por ciento en las SLLs), pone de manifiesto la relación entre los diferentes colectivos de socios en este tipo de entidades. Esta participación no se refleja en los trabajadores autónomos por sus características especiales. 
Gráfico 2: Participación de los diferentes colectivos vinculados con las sociedades en acciones RSC en los diferentes tipos de sociedades (CTA, SAL y SLL)

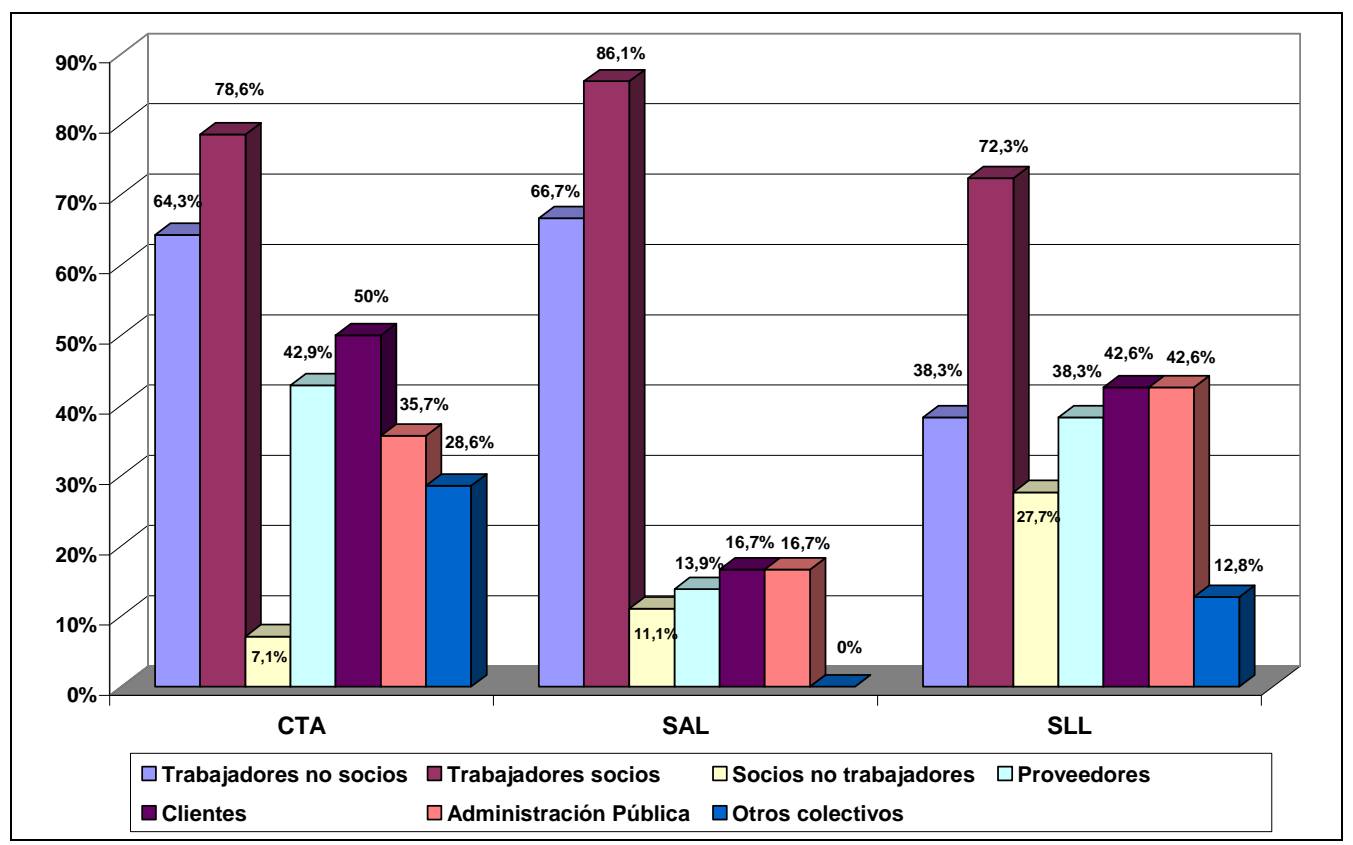

Analizando la valoración que realizan a los distintos colectivos únicamente las entidades que le asignan alguna participación, se obtiene la siguiente información:

- Los socios trabajadores, tal y como se ha mencionado, son el colectivo presente en un mayor número de acciones de RSC. Sin embargo, si se tiene en cuenta el grado de participación en las diferentes formas societarias se observa que entre el 82,9 y el 88,2 por ciento de las entidades manifiesta una participación reducida (grados 1 y 2). 
Gráfico 3: Valoración de la participación de los trabajadores socios en acciones RSC en los diferentes tipos de sociedades

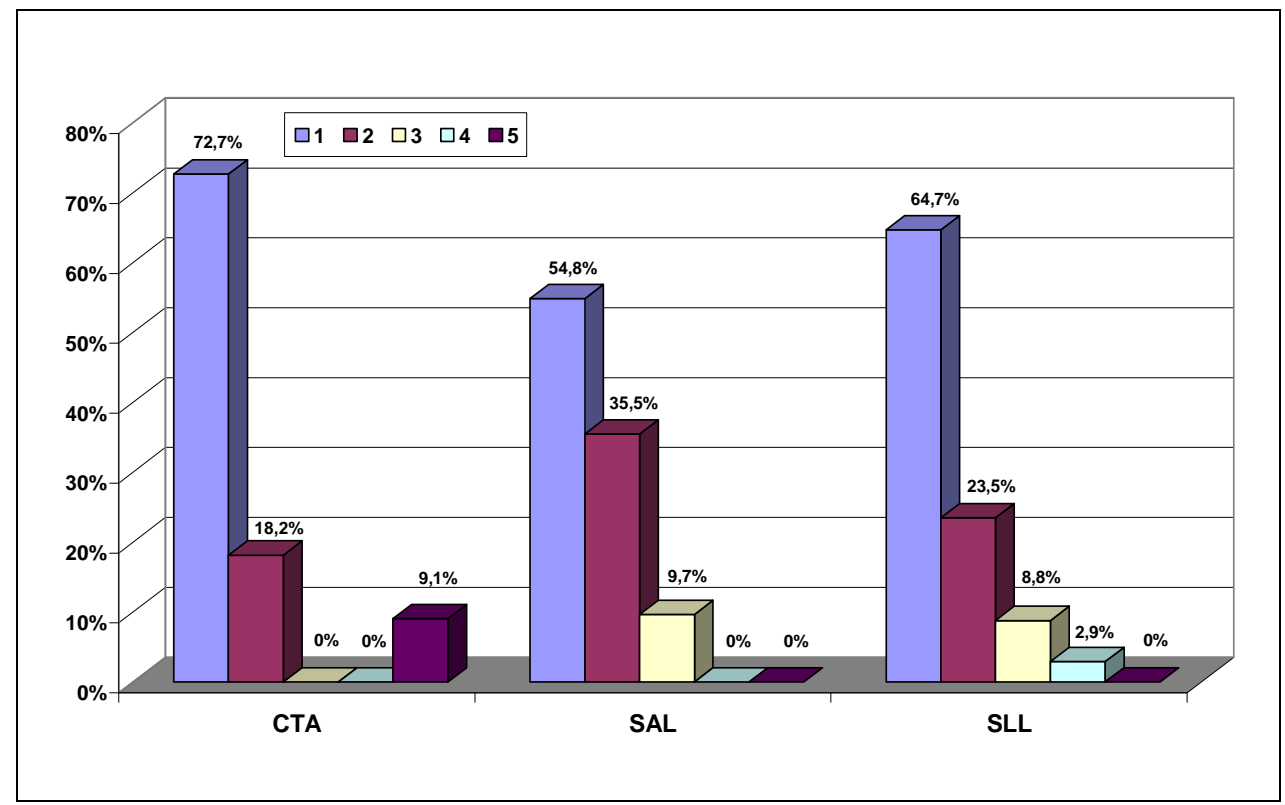

- En cuanto a los trabajadores no socios, aunque el numero de entidades que manifiesta su participación en estas acciones es inferior que las que recogen a los trabajadores socios, el nivel de implicación es muy similar. En esta línea se manifiestan, dentro de los grados 1 y 2 , entre el 88,8 y el 94,4 por ciento de las entidades. Esta circunstancia indica que muchas de estas medidas se extienden al resto de trabajadores de una forma muy similar a la de los propios socios trabajadores de las diferentes sociedades, buscando mejorar el clima laboral de las empresas. 
Gráfico 4: Valoración de la participación de los trabajadores no socios en acciones RSC en los diferentes tipos de sociedades

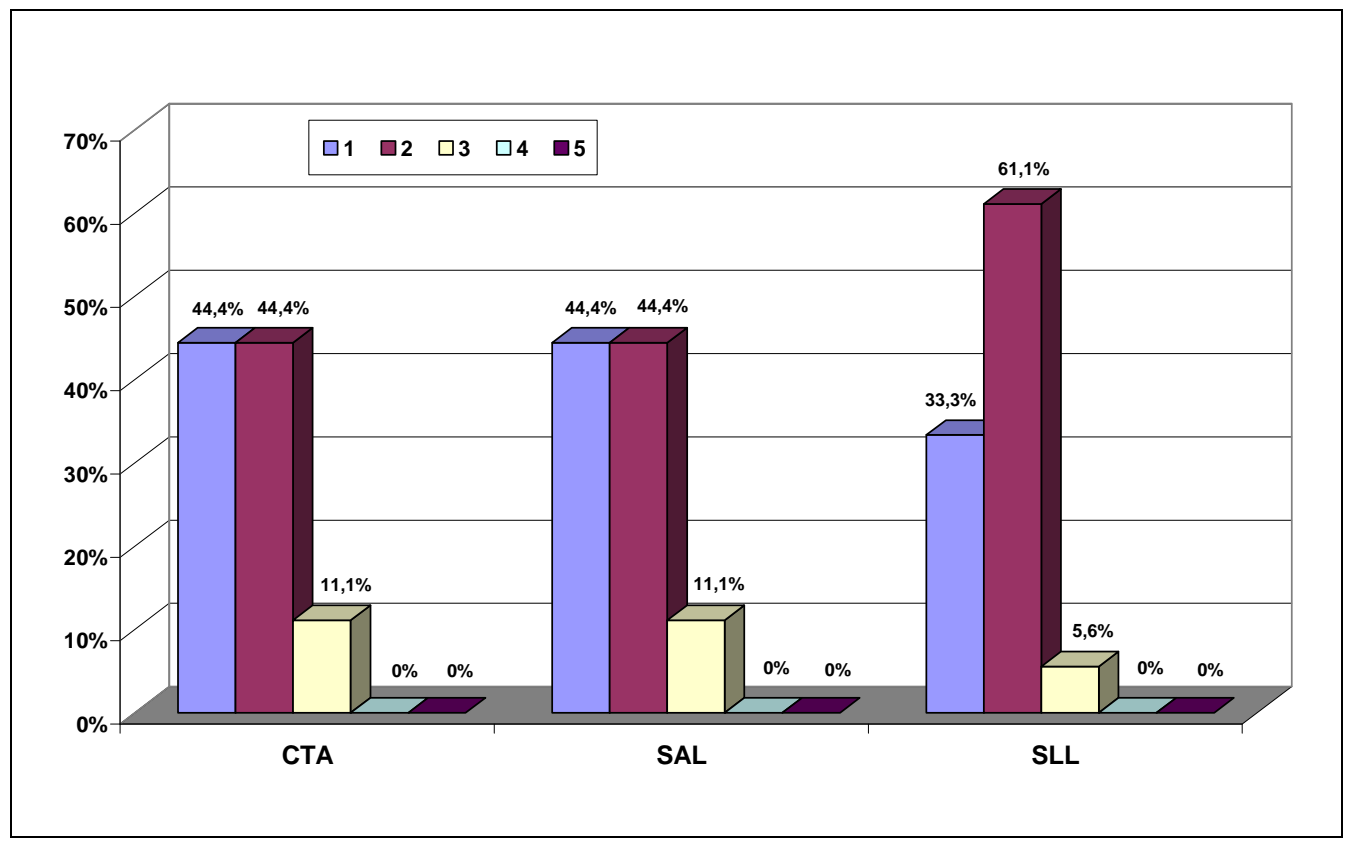

- En cuanto a los socios que sólo aportan capital, el porcentaje de entidades que manifiestan su participación en acciones de RSC se reduce a un 18,2 por ciento. En el nivel de participación, a la ya mencionada escasa participación en las SCTs, hay que añadir la unánime valoración en el grado inferior. El mayor valor se obtiene en las SLLs lo que indica que en este tipo de entidades la aplicación de medidas de RSC se extiende con más intensidad a los socios que solo aportan capital. Esta circunstancia tiene sentido si se considera que la reducida dimensión de estas entidades, con respecto a las SALs, supone una mayor importancia de este colectivo a la vez que repercute en un nivel de vinculación más elevado con los socios trabajadores. 
Gráfico 5: Valoración de la participación de los socios no trabajadores en acciones RSC en los diferentes tipos de sociedades

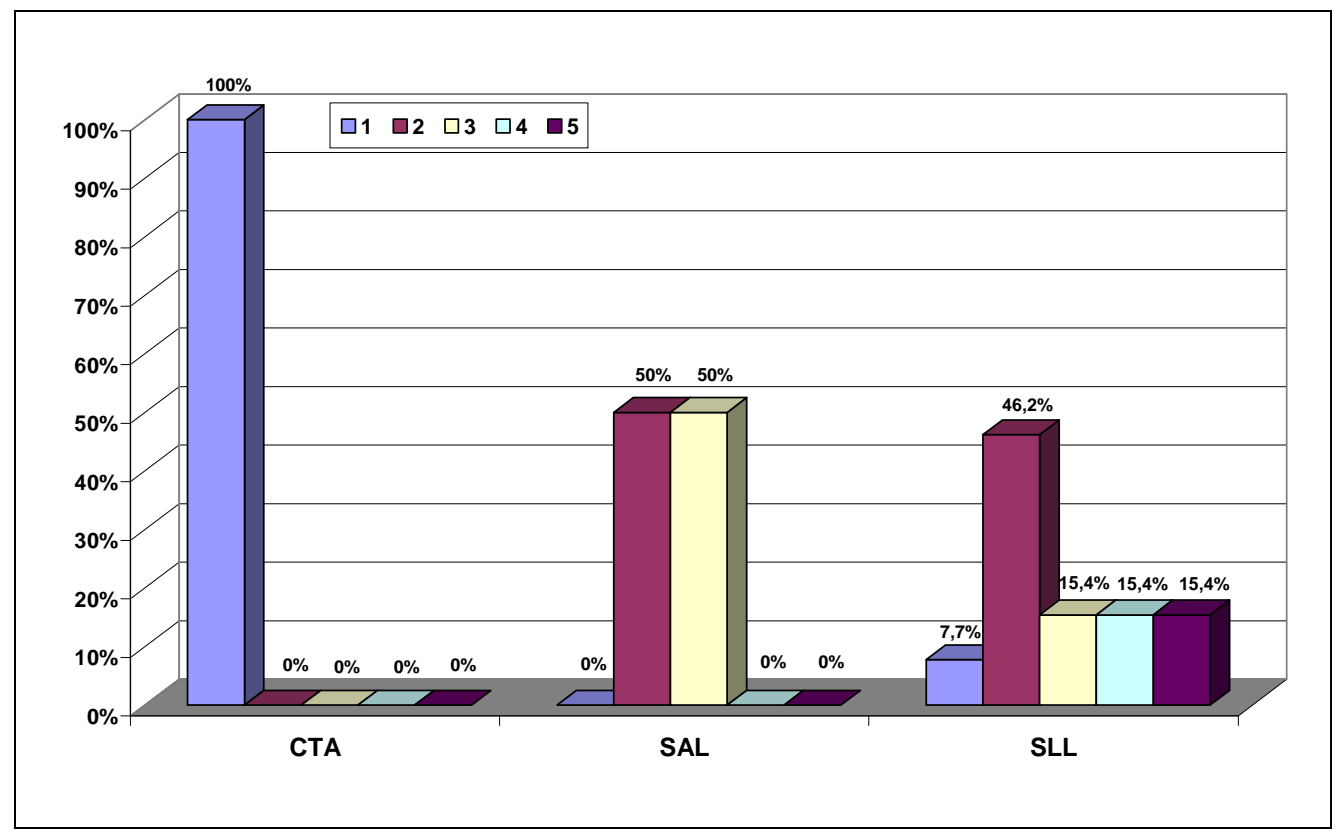

En cuanto a los restantes colectivos participantes en el proceso productivo, hay unanimidad en una mayor participación de los clientes (en un 35 por ciento de las entidades) mientras que la de los proveedores es manifestada por el 27 por ciento de las sociedades. El nivel de participación asignado a ambos colectivos es bastante más alto que en los casos anteriores, destacando especialmente la participación de los clientes en las SALs, donde cerca de un 94 por ciento de las entidades que manifiestan su participación sitúan ésta entre los grados 4 y 5, indicando la utilización de la RSC como herramienta comercial. En este sentido a pesar de que una de las utilidades de la RSC es la obtención de información útil para la gestión de la empresa, predomina su utilización como sistema de comunicación. Con ello se busca destacar, de cara a sus clientes que la actividad realizada por la empresa es respetuosa con las cuestiones sociales y ambientales. Este último aspecto es especialmente destacado en aquellas actividades en las que la materia prima y el proceso de elaboración son elementos claves para determinar la calidad del producto final. 
Gráfico 6: Valoración de la participación de los clientes en acciones RSC en los diferentes tipos de sociedades

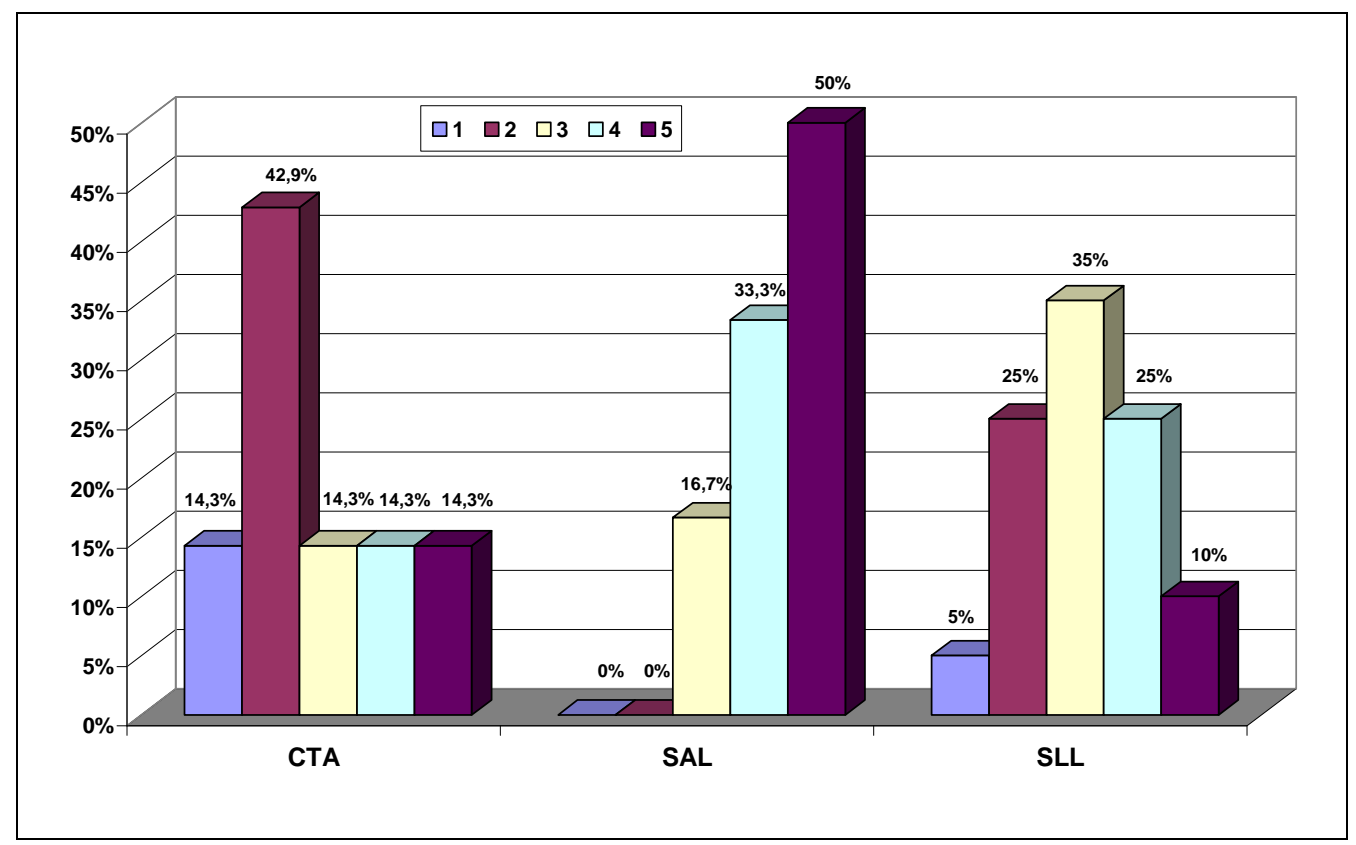

En cuanto a los proveedores, son también las SALs las que manifiestan un mayor nivel de participación (un 80 por ciento lo sitúan en los niveles 4 y 5). Este elevado peso se puede interpretar con una mayor implicación a la hora de contar con productos socialmente responsables como materias primas en el proceso productivo de este tipo de entidades.

Gráfico 7: Valoración de la participación de los proveedores en acciones RSC en los diferentes tipos de sociedades

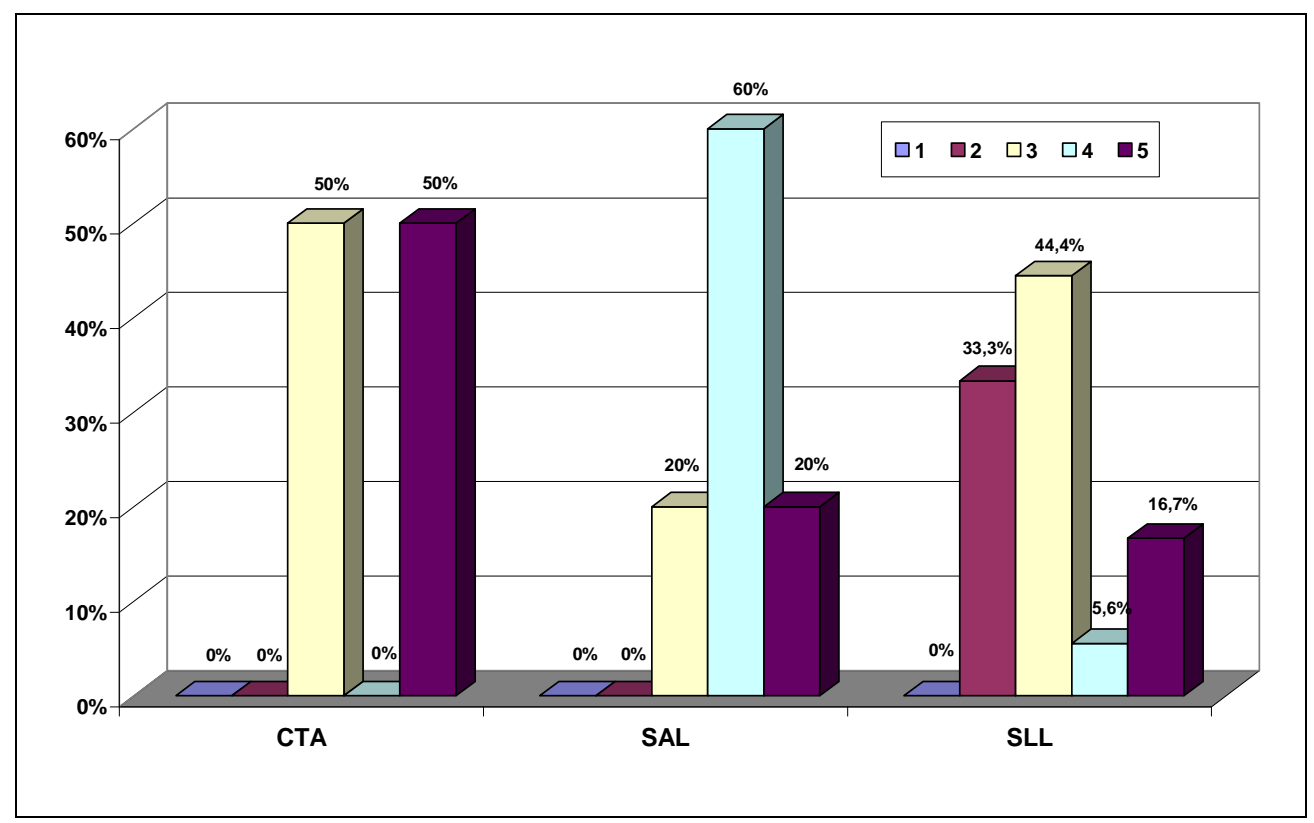


- La administración pública aparece implicada en las acciones de RSC para un 30 por ciento de las entidades. El nivel de participación es bastante elevado ya que entre el 22,3 y el 80 por ciento de las entidades le asigna valores lo hace entre 4 y 5 . Esta participación pone de manifiesto que las entidades de trabajo de la ciudad de Madrid son conscientes de la implicación y apoyo institucional de la Administración pública en el fomento de la RSC. Por último mencionar una pequeña participación de otros colectivos que sólo es recogida por un 10 por ciento de las entidades.

Gráfico 8: Valoración de la participación de la Administración Pública en acciones RSC en los diferentes tipos de sociedades

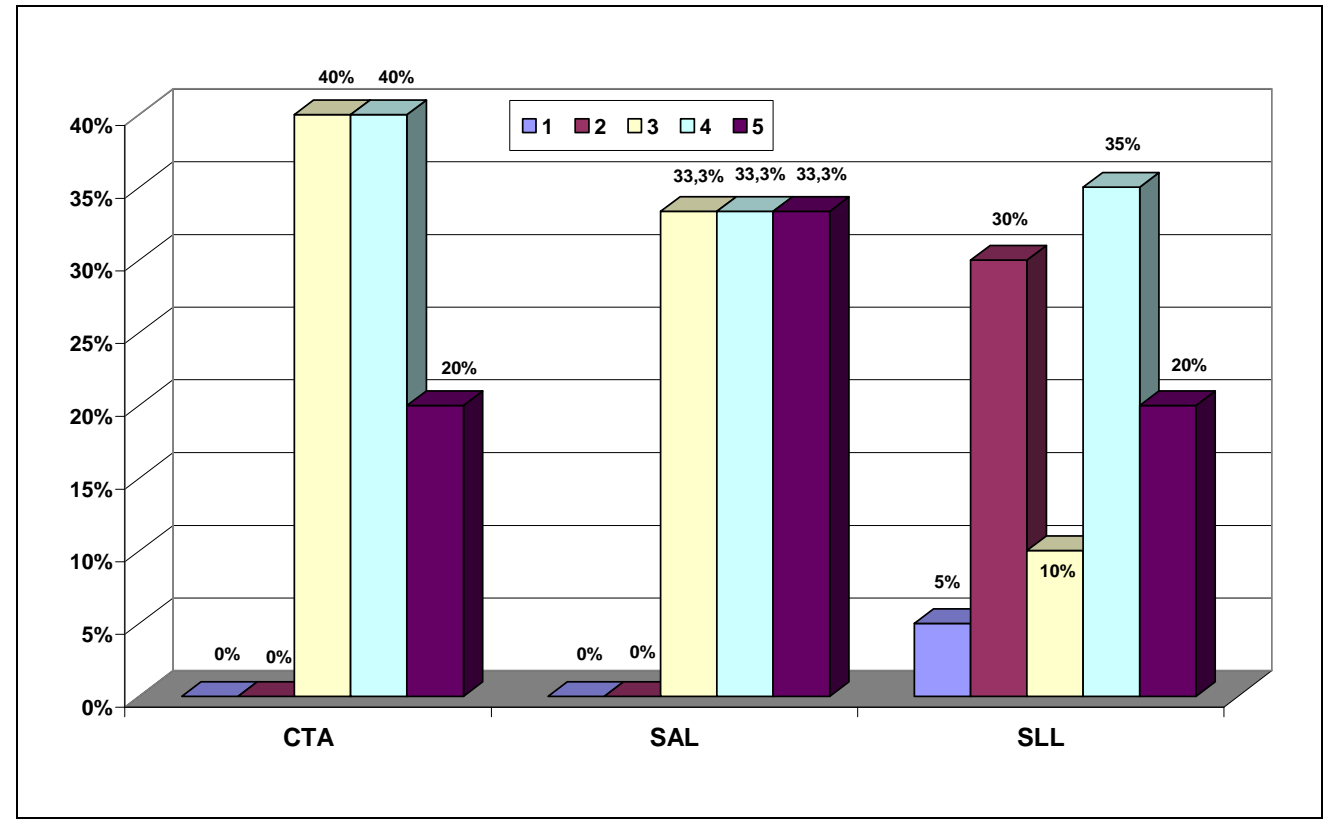

Por lo que respecta a la importancia de las diferentes dimensiones de la RSC se solicitó indicar de 1 a 5 (5 es la mayor) la importancia y preocupación que tienen las acciones sobre sostenibilidad vinculadas con las dimensiones económica, social y medioambiental. El resultado manifiesta que los tres aspectos tienen importancia para más del 86 por ciento de las entidades, siendo la dimensión económica la que despierta inquietud para un mayor número de entidades, concretamente un 90,7 por ciento seguida por la social ( 89,7 por ciento) y por la medioambiental (86,6 por ciento). Con ello queda patente como uno de los objetivos fundamentales de estas entidades asegurar las mejores condiciones tanto económicas como sociales. 
La distribución por tipos societarios es muy similar, siendo en la SCTs en las que presenta valores inferiores.

Gráfico 9: Importancia y preocupación por las acciones de sostenibilidad según los distintos tipos de sociedades

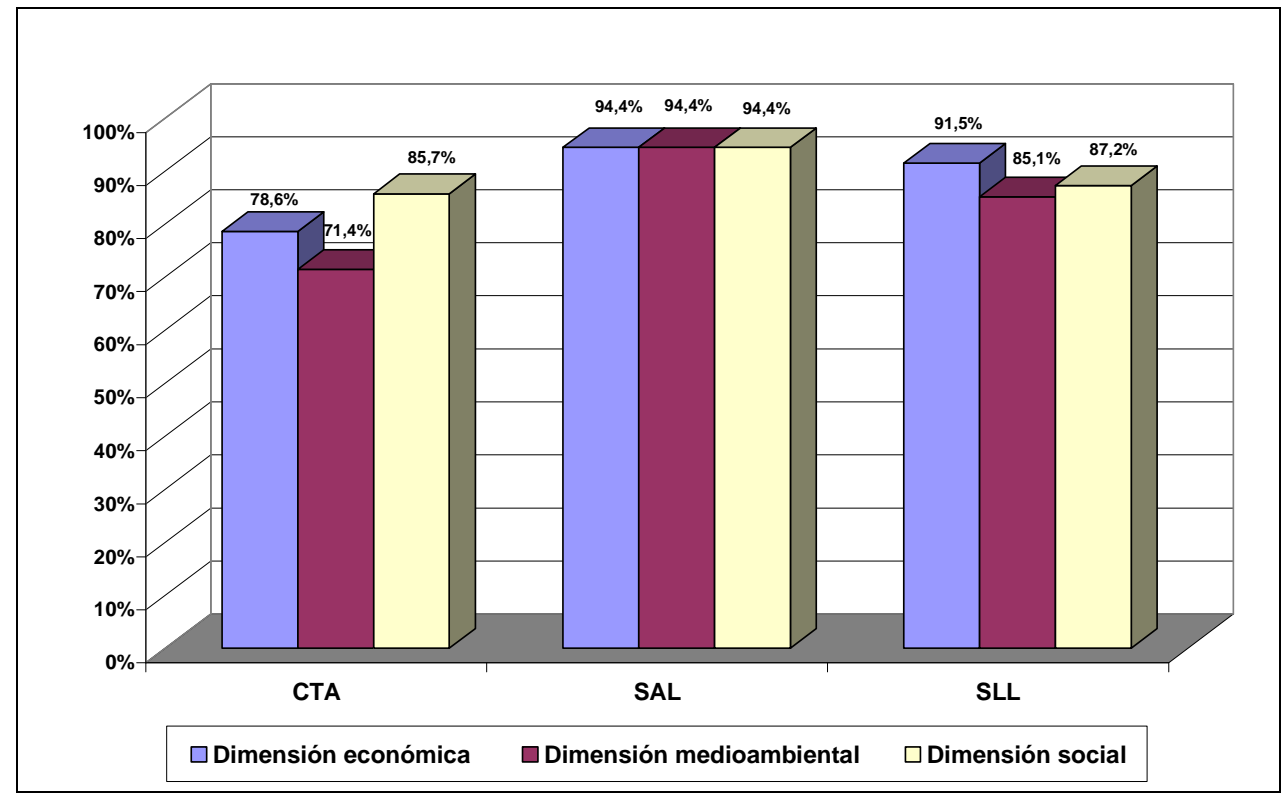

En cuanto al grado de importancia que asignan a cada dimensión, se observa que las dimensiones que preocupan a un mayor número de entidades (la económica y la social) son a las que se les otorga un menor grado de importancia. Así, cerca del 80 por ciento de las entidades le otorgan una importancia comprendida en los niveles 1 y 2. 
Gráfico 10: Valoración de la importancia y preocupación por la dimensión económica de las acciones de sostenibilidad según los distintos tipos de sociedades

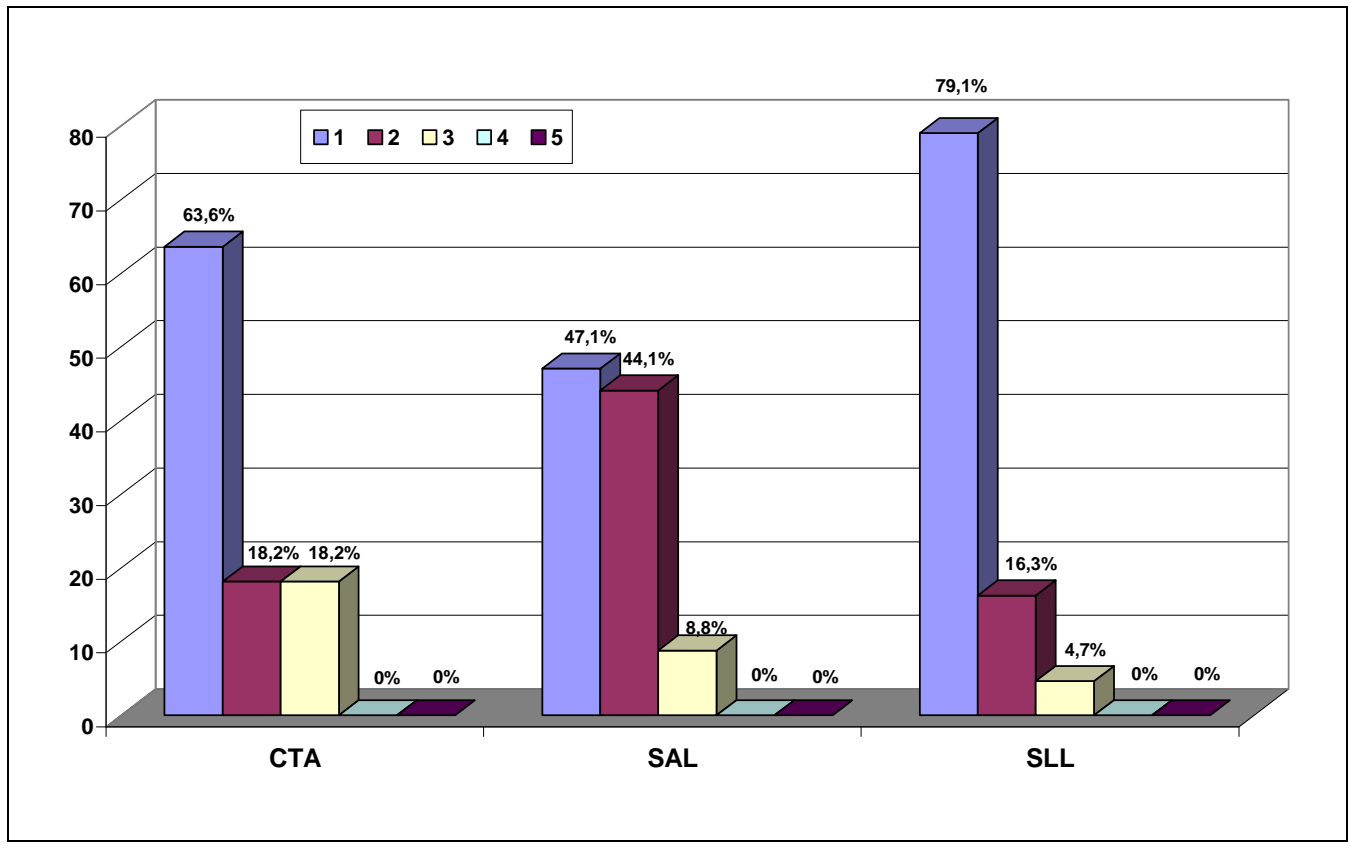

Gráfico 11: Valoración de la importancia y preocupación por la dimensión social de las acciones de sostenibilidad según los distintos tipos de sociedades

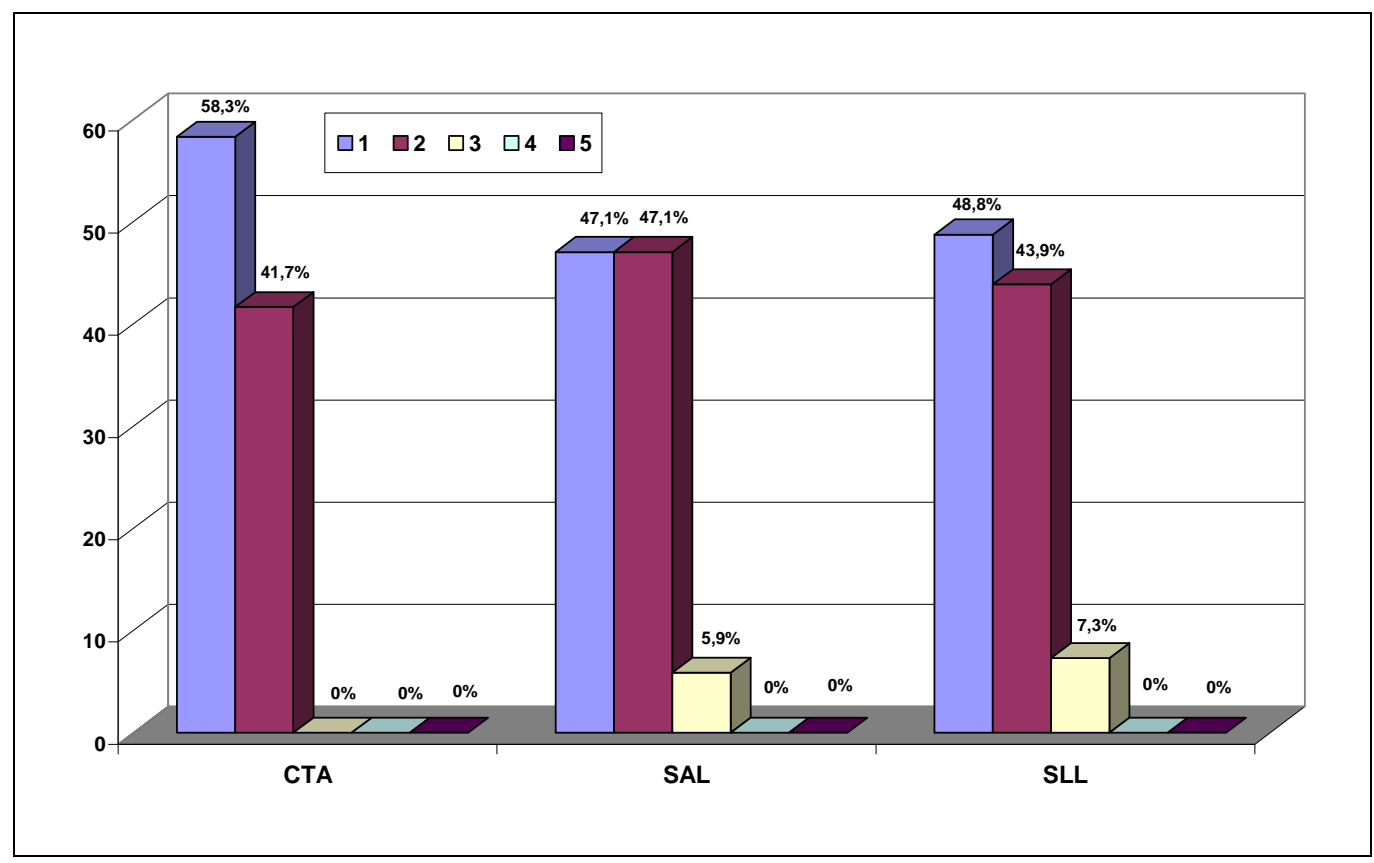

Por su parte, los aspectos ambientales, aunque preocupan a un menor número de entidades, lo son con una mayor valoración que en las restantes dimensiones. Destaca el caso de las SCTs que asignan valores entre 4 y 5 en el 30 por ciento de las entidades que manifiestan preocupación por estos temas. Esta circunstancia parece indicar que los aspectos ambientales juegan un papel especialmente importante para las sociedades cuyo proceso 
productivo se encuentra más ligado con actividades en las que la calidad de las materias primas o de los procesos productivos, juega un papel fundamental.

Gráfico 12: Valoración de la importancia y preocupación por la dimensión medioambiental de las acciones de sostenibilidad según los distintos tipos de sociedades

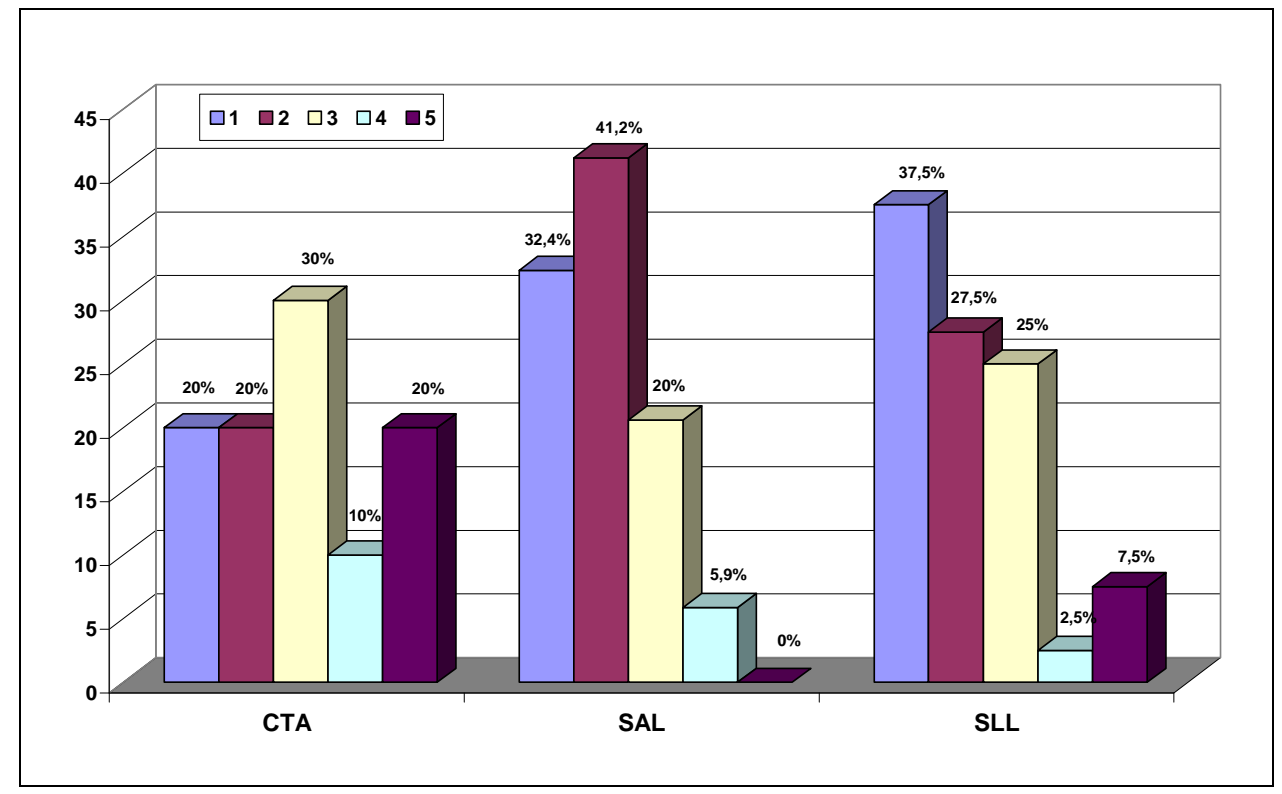

\section{CONCLUSIONES}

Las principales conclusiones extraídas del trabajo, en lo que respecta la valoración de las empresas de economía social sobre la responsabilidad social corporativa han sido las siguientes:

- Se han detectado por parte de las entidades encuestadas problemas para identificar los aspectos vinculados con la RSC. Así, en muchas ocasiones las entidades analizadas realizan acciones vinculadas con la responsabilidad social pero no las identifican con ella.

- Aunque el número de empresas de trabajo de la Ciudad de Madrid preocupadas por la RSC es elevado ( 94,5 por ciento), la valoración realizada por la misma es bastante reducida (el 64 por ciento le asignan un valor entre 1 y 2 y sólo el 16,09 por ciento valores entre 4 y 5). Esta circunstancia indica que existe una preocupación por la RSC, aunque es necesaria una mayor concienciación en cuanto a su importancia, especialmente como elemento para la creación de valor en la empresa a largo plazo. 
- La publicación de memorias de sostenibilidad o información destacable, en cualquiera de sus formatos, es uno de los aspectos que debe potenciarse, ya que el número de entidades que las publican es muy reducido. Ahora bien, muy probablemente dichas Memorias de Sostenibilidad, para ser viables en el ámbito de las estructuras empresariales analizadas en este estudio (pequeñas empresas y autónomos, principalmente), deben adquirir un formato y dimensión radicalmente distinto a los habituales en las grandes empresas. Por ello, pueden consistir en una mera enumeración de actuaciones e incluso de intenciones que la empresa realiza o plantea en el desarrollo de su actividad cotidiana.

- En cuanto a los distintos tipos de socios y trabajadores se observa que el colectivo que participa en acciones de RSC, en un mayor número de empresas, es el de los socios trabajadores, lo que deriva de la propia naturaleza de las entidades analizadas, basadas en la doble condición de socio y trabajador. Los trabajadores no socios le siguen en importancia, lo que indica que muchas de las medidas aplicadas a los trabajadores socios se extienden a los asalariados mejorando con ello el clima laboral. Sin embargo, la importancia que se asigna a su participación en ambos tipos de trabajadores es bastante más reducida que la que se otorga a otros colectivos. Por su parte la participación de los socios no trabajadores es bastante más reducida especialmente en las SCTs en las que se trata de una figura casi inexistente.

- En los restantes colectivos destaca la participación de los clientes tanto en número como en valoración. Esta circunstancia pone de manifiesto la utilización de la RSC como herramienta comercial con el fin de comunicar a sus clientes que su actividad es respetuosa con los aspectos de la RSC.

- El porcentaje de entidades analizadas que indican una participación de la administración pública es de algo más del 30 por ciento, aunque entre las entidades que manifiestan esta participación la valoración de la misma es muy elevada. Esta circunstancia indica que muchas de las entidades no conocen o no identifican con la RSC las actuaciones promovidas desde la Administración Pública, pero que aquellas que sí lo hacen las valoran de forma muy importante.

- La RSC es valorada en alguna de sus tres dimensiones por más del 85 por ciento de las entidades en un ejemplo más de la concienciación por este tipo de cuestiones. Las dimensiones valoradas por un mayor número de entidades son la 
económica y la social, aunque es la medioambiental la que presenta mayores niveles de importancia entre las entidades que muestran preocupación por las mismas.

\section{BIBLIOGRAFÍA}

CARROLL, A.B. Corporate Social Responsability. Evolution of a Definitional Construct. Business \&Society, V. 38(3). 1999, p. 268-295.

CASTILlO, A. La responsabilidad social de la empresa en el contexto social: su articulación, gestión y control. Tesis Doctoral, Universidad de Málaga, Facultad de Ciencias Económicas y Empresariales. 1985.

CECU. La opinión y valoración de los consumidores sobre la responsabilidad social de la empresa en España. Madrid: CECU, 1985.

COMISIÓN DE LA COMUNIDADES EUROPEAS. Comunicado de la Comisión al Parlamento Europeo, al Consejo y al Comité Económico y Social Europeo. Poner en práctica la asociación para el crecimiento y el empleo: Hacer de Europa un polo de excelencia de la responsabilidad social de las empresas COM (2006) 136 final, Bruselas 22 de marzo de 2006.

COMUNIDADES EUROPEAS. Dictamen del Comité Económico y Social sobre el Libro Verde - Fomentar un marco europeo para la responsabilidad social de las empresas D.O.C.E. C de 27 de mayo de 2002.

CUESTA DE LA, M; VALOR, M.; SANMARTIN, S. Inversiones éticas en empresas socialmente responsables. Madrid: Universidad Nacional de Educación a Distancia, 2002.

CUESTA, DE LA, M.; VALOR, C. Fostering corporate social responsibility through public initiative: from the EU to the Spanish case. Journal of Business Ethics, 55-3, 2004, p. 275-29.

DOMINI SOCIAL INVESTMENT. 2000 Social screening criteria, Estados Unidos: Domini Social Investment, 2000.

ESPAÑA: LEY 27/1999, de 16 de julio, de Cooperativas, B.O.E. N. 170, de 17 de julio.

GARCIA-GUTIÉRREZ FÉRNANDEZ, C. Análisis de la rentabilidad económica y financiera de los socios de las cooperativas: La influencia de una rentabilidad en la otra y la 
aplicación del criterio (principio) de justicia -que no de solidaridad- en la distribución de la ganancia real, Revista Europea de Economía de la Empresa, Vol. 1, nº 2.

GARCÍA-GUTIÉRREZ FERNÁNDEZ, C. El problema de la doble condición de sociostrabajadores (socios-proveedores y socios -consumidores) ante la gerencia de la empresa cooperativa. REVESCO, Revista de Estudios Cooperativos, nº 56 y 57, 1988-1989.

GLOBAL REPORTING INITIATIVE. Guía para la elaboración de Memorias de Sostenibilidad. Holanda: Global Reporting Initiative, 2006. Disponible en Internet: http://www.globalreporting.org/INSTITUTO ETHOS. Indicadores ETHOS de responsabilidad social empresarial 2006.

Brasil: Instituto Ethos, 2006. Disponible en Internet: http://www.ethos.org.br

LEWIS, A. Moral, markets and Money. Londres: Prentice Hall, 2002.

MORALES GUTIÉRREZ, A.C.: La cooperativa como realidad social, ideológica y económica. Córdoba: Colección Tesis Doctorales, Publicaciones ETEA, 1991.

SOCIAL INVESTMENT FORUM. Reports on Socially Responsible Investing Trends in the United States. Washington: SIF Industry Research Program, 2004. Disponibles en Internet: http://www.socialinvest.org/resources/research

VALOR MARTÍNEZ, C.; PALOMO ZURDO, R.J. Las empresas de participación y la inversión socialmente responsable: efectos de los criterios de regulación y asimetrías de información. REVESCO Revista de Estudios Cooperativos, 80, 2003, p. 107-124.

VALOR, C; GARCÍA, J.C; ISABEL D; ITURRIOZ, J; MATEU, J.L; MERINO, A; PALOMO R. Inversión Socialmente responsable en las entidades financieras de Economía Social. Madrid: Universidad CEU-San pablo, Madrid, 2005. 